\title{
Liquid-Plasma Hydrogenated Synthesis of Gray Titania with Engineered Surface Defects and Superior Photocatalytic Activity
}

\author{
Feng Zhang ${ }^{1,+}$, Guang Feng ${ }^{2,3,+}+$, Mengyun Hu ${ }^{1,3}$, Yanwei Huang ${ }^{1,3}$ and Heping Zeng $1,2,3,4, *$ \\ 1 State Key Laboratory of Precision Spectroscopy, East China Normal University, Shanghai 200062, China; \\ 18843156039@163.com (F.Z.); myhu@phy.ecnu.edu.cn (M.H.); ywhuang@lps.ecnu.edu.cn (Y.H.) \\ 2 Shanghai Key Laboratory of Modern Optical System, Engineering Research Center of Optical Instrument \\ and System, Ministry of Education, School of Optical-Electrical and Computer Engineering, University of \\ Shanghai for Science and Technology, Shanghai 200093, China; sunnyfeng1992@163.com \\ 3 Chongqing Institute of East China Normal University, Chongqing 401120, China \\ 4 CAS Center for Excellence in Ultra-Intense Laser Science, Shanghai 201800, China \\ * Correspondence: hpzeng@phy.ecnu.edu.cn; Tel.: +86-021-6223-2108 \\ + These authors contributed equally to this work.
}

Received: 19 January 2020; Accepted: 13 February 2020; Published: 17 February 2020

\begin{abstract}
Defect engineering in photocatalysts recently exhibits promising performances in solar-energy-driven reactions. However, defect engineering techniques developed so far rely on complicated synthesis processes and harsh experimental conditions, which seriously hinder its practical applications. In this work, we demonstrated a facile mass-production approach to synthesize gray titania with engineered surface defects. This technique just requires a simple liquid-plasma treatment under low temperature and atmospheric pressure. The in situ generation of hydrogen atoms caused by liquid plasma is responsible for hydrogenation of $\mathrm{TiO}_{2}$. Electron paramagnetic resonance (EPR) measurements confirm the existence of surface oxygen vacancies and $\mathrm{Ti}^{3+}$ species in gray $\mathrm{TiO}_{2-x}$. Both kinds of defects concentrations are well controllable and increase with the output plasma power. UV-Vis diffused reflectance spectra show that the bandgap of gray $\mathrm{TiO}_{2-\mathrm{x}}$ is $2.9 \mathrm{eV}$. Due to its extended visible-light absorption and engineered surface defects, gray $\mathrm{TiO}_{2-x}$ exhibits superior visible-light photoactivity. Rhodamine $\mathrm{B}$ was used to evaluate the visible-light photodegradation performance, which shows that the removal rate constant of gray $\mathrm{TiO}_{2-\mathrm{x}}$ reaches $0.126 \mathrm{~min}^{-1}$ and is 6.5 times of $\mathrm{P} 25 \mathrm{TiO}_{2}$. The surface defects produced by liquid-plasma hydrogenation are proved stable in air and water and could be a candidate hydrogenation strategy for other photocatalysts.
\end{abstract}

Keywords: surface defect; oxygen vacancy; gray titania; liquid plasma; visible light

\section{Introduction}

Titanium dioxide $\left(\mathrm{TiO}_{2}\right)$ due to its nontoxic, high stability, and high photocatalytic performance is considered as a promising photocatalyst, which has been widely used in environmental remedies and water splitting [1-3]. However, the photoactivity of $\mathrm{TiO}_{2}$ is largely limited by its wide bandgap $(3.2 \mathrm{eV})$ and only responds to UV light, nearly $4 \%$ part of solar energy, which severely restricts its practical applications. In order to enhance solar light absorption, much effort has been devoted to bandgap engineering, by means of noble metal $(\mathrm{Au}, \mathrm{Pt}, \mathrm{Ag}$, etc.) and nonmental (N, S, I, etc.) doping, artificial crystal structure modification, and carbonaceous nanomaterial compositing (carbon nanotubes, graphene, and fullerenes) [4-10]. Nevertheless, the visible-light energy conversion remains insufficient due to little solar light absorption and many carrier-recombination centers [11,12]. In recent years, black $\mathrm{TiO}_{2}$ has gained enormous attention owing to its extraordinary visible and infrared 
light absorption, prompting superior performances in photodegradation and water splitting [13-15]. The enhanced solar light absorption of black $\mathrm{TiO}_{2}$ is ascribed to additional intermediate electronic states (e.g., $\mathrm{V}_{\mathrm{o}}$ or $\mathrm{Ti}^{3+}$ states) and disorder surface caused by hydrogenation [16-18]. More importantly, defect engineering, for instance defects concentration and distribution, also plays an important role in tuning photocatalytic activity of black $\mathrm{TiO}_{2}$. It was reported that the high defect ratio of surface to bulk can significantly enhance the photoactivity owing to preferential diffusion from bulk to surface of photoinduced charges [19,20]. However, surface defects are not stable enough as it can be spontaneously oxidized in air and water. So far, mainstream strategies to synthesize black/gray $\mathrm{TiO}_{2-x}$ are relied on the reduction of pristine stoichiometric $\mathrm{TiO}_{2}$ [20-24], such as annealing under high pressures of $\mathrm{H}_{2}$ or $\mathrm{NH}_{3}$, high-energy particle bombardment (hydrogen plasma, laser plasma, or high-energy electrons), and chemical reduction with reducing agent in vacuum. Apparently, it is significant and desirable to develop a simple and feasible strategy for massive production of black/gray $\mathrm{TiO}_{2-x}$ with engineered surface defects and related abundant solar absorption.

Hereafter, we conduct a one-pot synthesis of gray $\mathrm{TiO}_{2-x}$ with large solar harvesting and engineered surface defects using a liquid-plasma technology at room temperature and atmospheric pressure [25]. There has recently been increasing interest in liquid-plasma discharges and their potential applications in various technologies, including environmental remediation, nanomaterial synthesis, and surface processing [26-28]. One of the most important advantages of liquid plasma is that various reactions instantaneously occur, including active species oxidation (e.g., $\mathrm{OH}, \mathrm{O}, \mathrm{H}_{2} \mathrm{O}_{2}$, etc.), ultraviolet radiation, electric fields, and shock waves. The synergy among those intense reactions is considered to possess a much higher efficiency than traditional chemical methods. In addition, liquid plasma provides an environmentally green and safe method, as fabrication itself consumes no extra chemicals and produces no chemical residuals.

We got mass production of black/gray $\mathrm{TiO}_{2-x}$ via liquid plasma driven by a bipolar pulse power. The synthesis setup, as shown in Figure 1A, is quite simple and it requires no complicated vacuum chambers, no reducing gas, or reagents. The bright liquid plasma was generated on the surface of metallic titanium electrode by applying high voltage pulses with high frequency as shown in Figure 1B. The typical generation procedure of liquid plasma can be detailed as follows. When appropriate pulse voltages were applied, some vapors were formed to cover the cathodes surface, i.e., "gas sheath", by the Joule heating effect [29]. The "gas sheath" breakdown took place with the increase of electrolyte temperature and input voltage, and concurrently, glow discharge was generated near the cathodes surface. The temperature of cathode plasma was estimated to be $2000-3000 \mathrm{~K}$ according to previous studies [30,31]. Afterwards, cathodic plasma dissociated water molecules to produce the hydrogen environment at/near the plasma region [32]. After $1 \mathrm{~h}$ of liquid-plasma treatments, the color of $300 \mathrm{~g}$ anatase titania was varied from white to dark gray, and the digital pictures of dry powder samples are shown in Figure 1C. Figure 2 shows the optical emission spectrum of liquid plasma and clearly exhibits various emission peaks attributed to Ti I (neutral), Ti II (single-charged ions), hydroxyl radicals, hydrogen, and atomic oxygen, which were originated from the interaction between plasma and liquid. Thus, we hypothesize that white $\mathrm{TiO}_{2}$ nanoparticles dissolved in electrolyte entered the hot plasma area, and thus underwent plasma thermal treatment and hydrogenation at/near the plasma region. This synergy played a significant role in synthesizing gray $\mathrm{TiO}_{2-x}$, and the synthesis mechanism of gray $\mathrm{TiO}_{2-x}$ is depicted in Figure 2. From EPR measurements, a tunable surface-defect concentration of $\mathrm{TiO}_{2-x}$ was achieved by applying a different plasma discharge power. Interestingly, even though surface defects are easily oxidized under strong oxidation environments, these surface defects generated through the liquid-plasma strategy were verified as quite stable. 


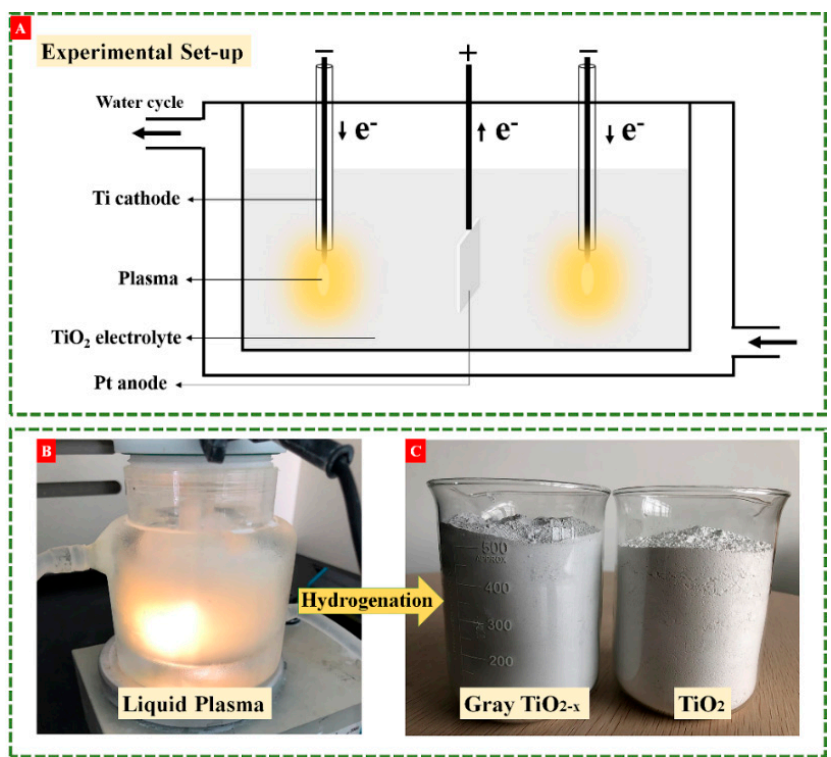

Figure 1. (A) The setup for liquid plasma generation, (B) digital picture of as-produced liquid plasma, and $(\mathbf{C})$ digital pictures for gray titanium dioxide $\left(\mathrm{TiO}_{2-\mathrm{x}}\right)$ and pristine white $\mathrm{TiO}_{2}$.

\section{Schematic of liquid plasma hydrogenation}

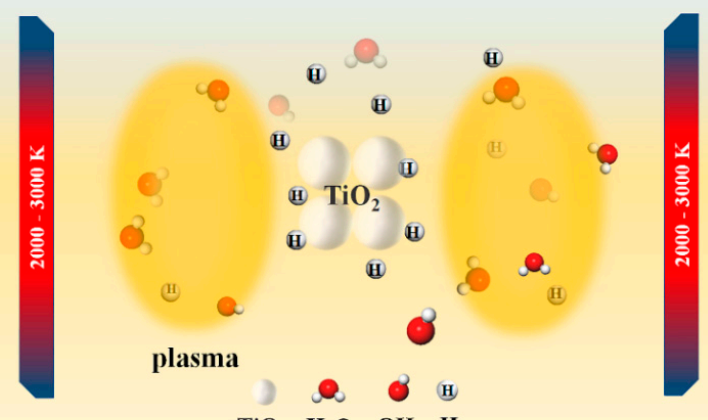

$\mathrm{TiO}_{2} \mathrm{H}_{2} \mathrm{O}$ OH $\mathrm{H}$

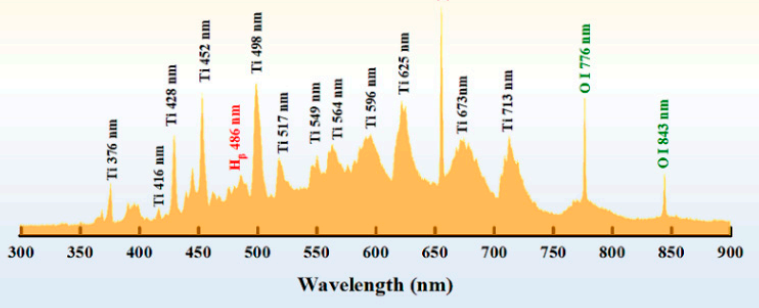

2. Color variations of $\mathrm{TiO}_{2}$ nanoparticle

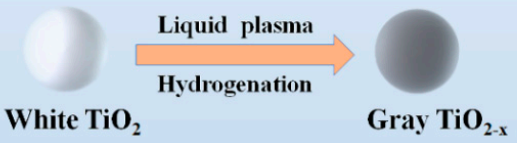

Figure 2. The synthesis mechanism of gray $\mathrm{TiO}_{2-x}$ nanosphere assisted by liquid plasma and the corresponding optical emission spectrum originated from cathodic Ti electrodes. 


\section{Experimental Section}

\subsection{Preparation of Gray $\mathrm{TiO}_{2-x}$}

Commercial white anatase $\mathrm{TiO}_{2}$ nanopowders were bought from Shanghai Xieqing industrial Co., Ltd.(Shanghai, China), with $30 \mathrm{~nm}$ average size. $\mathrm{P} 25 \mathrm{TiO}_{2}$ of 20-30 nm was bought from Degussa Corp, which consisted of $78 \%$ anatase and $28 \%$ rutile. Briefly, we mixed $300 \mathrm{~mL}$ of $100 \mathrm{mg} / \mathrm{mL}$ well-dispersed anatase $\mathrm{TiO}_{2}$ solution and $7 \mathrm{~mL}$ of $0.1 \mathrm{~mol} / \mathrm{L}$ nitric acid to get the electrolyte, which was afterwards transferred to electrolytic cell. One anodic platinum sheet $\left(20 \times 20 \times 1 \mathrm{~mm}^{3}, 99.99 \%\right)$ and two cathodic titanium rods (4-mm diameter, 99.9\%) were sealed into a corundum tube in 300-mL nitric acid electrolyte as shown in Figure 1A. Two cathodes were used to generate glow discharges and avoid unbalanced flow and temperature gradients in the electrolyte. The $\mathrm{HNO}_{3}$ electrolyte here acted as a conductive solution. Pulsed voltages were applied between anode and cathodes to produce intense plasma nearby the cathode surfaces. Liquid plasma was produced on the cathode surface when we applied an appropriate pulse voltage power $(600 \mathrm{~V})$. The produced plasma whose intensity is dependent on glow discharge power, induces the high temperature at plasma-electrolyte interface and hydrogen generation. To avoid the electrolyte evaporation, a water chiller was used to maintain the electrolyte temperature at $80{ }^{\circ} \mathrm{C}$. The color of $\mathrm{TiO}_{2}$ electrolyte gradually turned from white to dark gray within $1 \mathrm{~h}$. The reaction mechanism for the formation of gray $\mathrm{TiO}_{2-\mathrm{x}}$ can be ascribed to the hydrogenation effect of liquid plasma. Briefly, $\mathrm{TiO}_{2}$ nanopowders well dispersed in electrolyte took disordered movements due to intense liquid-plasma shockwaves. Some $\mathrm{TiO}_{2}$ nanoparticles moved to the plasma region and underwent hydrogenation under high temperature (2000-3000 K) owing to the hydrogen environment derived from water dissociation. Then, large numbers of nanoparticles repeated plasma hydrogenation treatments and hydrogenated gray $\mathrm{TiO}_{2-x}$ from white $\mathrm{TiO}_{2}$ was finally obtained. Hereafter, we dubbed the sample according to the output plasma power, for example GT-360 refers to gray $\mathrm{TiO}_{2-x}$ obtained by applying an output plasma power of $360 \mathrm{~W}$.

\subsection{Characterization}

The phase and crystallinity for all samples were tested by the X-ray powder diffraction (XRD) using a Rigaku Smartlab (Rigaku, Tokyo, Japan) machine equipped with Cu Ka irradiation $(\lambda=$ $1.54056 \AA$ A). The morphology was characterized by TEM using a JEM-2500SE (JEOL, Tokyo, Japan) instrument operating at an acceleration voltage of $200 \mathrm{kV}$. UV-Vis diffused reflectance spectra were measured by the Shimadzu UV-2700 spectrophotometer at a wavelength range of 200-800 $\mathrm{nm}$ at room temperature. The Raman spectra of samples were recorded by Thermo scientific DXR Raman microscope with 532-nm laser excitation at room temperature. The X-ray photoelectron spectra (XPS) were recorded with thermos Escalab 250Xi. The existence of defects doped in the $\mathrm{TiO}_{2-x}$ nanoparticles was confirmed by the X-band EPR spectra recorded at room temperature. The plasma discharges were controlled by applying square-wave voltages between titanium cathodes and $\mathrm{Pt}$ anode, with variable pulsed voltage of $0 \sim 800 \mathrm{~V}$, pulsed current of $0 \sim 5 \mathrm{~A}$, and repetition rate of $0 \sim 5 \mathrm{kHz}$. The voltage was increased at a ratio of $20 \mathrm{~V} / \mathrm{s}$.

\subsection{Visible-Light Photocatalytic Degradation}

The evaluation of visible-light photoactivity was individually tested with three typical waste-water pollutants, including rhodamine B (RhB), methyl orange (MO), and phenol. We used a 300-W Xenon lamp with a 420-nm cutoff filter as the visible-light source. Degussa P25 $\mathrm{TiO}_{2}$ was used as a standard photocatalyst for photoactivity comparison with as-prepared samples. The concentrations of $\mathrm{RhB}, \mathrm{MO}$, and phenol were 20, 20, and $10 \mathrm{mg} / \mathrm{L}$, respectively. Firstly, $50 \mathrm{mg}$ as-prepared $\mathrm{TiO}_{2-x}$ nanopowders and $50 \mathrm{~mL}$ of pollutant solution were put in a 500-mL beaker. Before illumination, the mixture was placed in a dark environment for $30 \mathrm{~min}$ with magnetic stirring for adsorption-desorption equilibrium. During photodegradation, we took out 1-mL of solution in the glass every $10 \mathrm{~min}$ and centrifuged it at 10,000 rpm for $11 \mathrm{~min}$. Finally, the concentration of pollutant solution was analyzed at a specific 
wavelength by the UV-2700 spectrophotometer, where RhB, MO, and phenol are located at 554, 464, and $270 \mathrm{~nm}$, respectively. Photodegradation experiments for whole tested samples were carried out under the same conditions.

\section{Results and Discussion}

The crystal structures of gray $\mathrm{TiO}_{2-x}$ obtained at different plasma discharge powers were detected by XRD analysis as shown in Figure 3. The XRD patterns of the as-grown gray $\mathrm{TiO}_{2-x}$ exhibit characteristic diffraction peaks matching the (101), (103), (004), (112), (200), (105), (211), (204), (116), (220), (215) facets of anatase crystal without any additional diffraction peaks, showing identical diffraction peaks with pristine $\mathrm{TiO}_{2}$. In addition, the full width at half maximum and height (FWMH), as well as the integrated peak area of the diffraction peak at 101 facets are nearly unchanged after plasma treatments as seen in Table S1 (see Support Information). This result indicates liquid plasma treatments neither destroy the long-range order lattice structure nor enlarge nanoparticle size of gray $\mathrm{TiO}_{2-x}$.

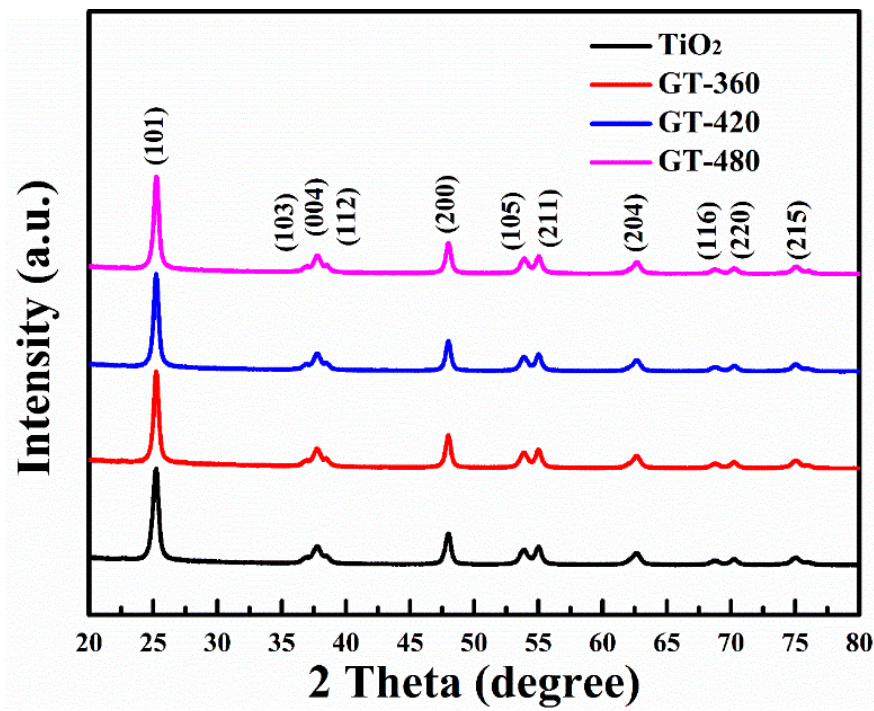

Figure 3. XRD diffraction patterns of gray $\mathrm{TiO}_{2-x}$ samples prepared with different glow discharge powers, and black line refers to anatase $\mathrm{TiO}_{2}$.

The morphology and lattice information of pristine $\mathrm{TiO}_{2}$ and gray $\mathrm{TiO}_{2-x}$ nanoparticles are presented in Figure 4A-D. Figure 4A shows that pristine $\mathrm{TiO}_{2}$ nanoparticles possessed serious agglomeration. Conversely, as shown in Figure 4B, little agglomeration was observed in gray $\mathrm{TiO}_{2-x}$, which could be ascribed to increasement of surface energy in nanoparticles owing to plasma treatments. Both pristine $\mathrm{TiO}_{2}$ and gray $\mathrm{TiO}_{2-x}$ nanocrystals are on average $\sim 30 \mathrm{~nm}$ in diameter, which is well consistent with XRD measurements and suggests that hot temperature in liquid plasma does not prompt $\mathrm{TiO}_{2}$ crystal growth. Figure 4C,D present the high-resolution morphological structures of pristine $\mathrm{TiO}_{2}$ and $\mathrm{TiO}_{2-x}$ nanoparticles. From Figure $4 \mathrm{C}$, marginal defects of pristine $\mathrm{TiO}_{2}$ are observed and could be produced during the crystal growth procedure. As indicated in Figure 4D, it seems that a thin disorder shell, nearly 1-2 nm in thickness, appears on the gray $\mathrm{TiO}_{2-\mathrm{x}}$ surface, while the bulk maintains good crystallinity.

The UV-Vis diffuse reflectance spectra (DRS) are used to evaluate the light absorption properties of gray $\mathrm{TiO}_{2-x}$ samples. As shown in Figure $5 \mathrm{~A}$, pristine $\mathrm{TiO}_{2}$ shows merely ultraviolet light absorption, while all as-prepared gray $\mathrm{TiO}_{2-x}$ samples exhibit a broadband absorption from ultraviolet to visible even infrared regions. Moreover, from the inset of Figure $5 \mathrm{~A}$, the as-prepared $\mathrm{TiO}_{2-x}$ gradually exhibited a deepened color with the change of output power from 360 to $480 \mathrm{~W}$. Figure 5B plots $(\alpha \mathrm{h} v)^{1 / 2}$ versus hv by using the Kubelka-Munk function [33]. From which we calculate the bandgap of pristine $\mathrm{TiO}_{2}$, GT-360, GT-420, and GT-480 as 3.14, 3.07, 3.00, and $2.90 \mathrm{eV}$, respectively. Apparent red-shifts were 
observed for the absorption edge of gray $\mathrm{TiO}_{2-x}$ compared with pristine $\mathrm{TiO}_{2}$. The higher discharge power is, the narrower bandgap of gray $\mathrm{TiO}_{2-x}$ is obtained. The decreased bandgap in our case implies some self-doped crystal defects, for instance oxygen vacancy and/or $\mathrm{Ti}^{3+}$ centers, has been produced after plasma hydrogenation. Since self-doped defects inevitably introduce doped states between the bandgap such as oxygen-vacancy and $\mathrm{Ti}^{3+}$ induced intermedium states, which accounts for the visible-light absorption of gray $\mathrm{TiO}_{2-x}$. The color depth of defective $\mathrm{TiO}_{2-x}$ is reported and can be related to the amount of surface defects, which plays a role of "color centers", and the more surface defects $\mathrm{TiO}_{2-x}$ possesses, the more visible light $\mathrm{TiO}_{2-x}$ captures $[34,35]$. To verify the existence of surface defects, gray $\mathrm{TiO}_{2-x}$ was heated at $300{ }^{\circ} \mathrm{C}$ under atmosphere for $3 \mathrm{~h}$. Unexpectedly, the color was changed from gray to white, which can be attributed to the fact that surface defects diffuse from surface to bulk or can be oxidized by air. Thus, we conclude that some surface defects most likely exist in gray $\mathrm{TiO}_{2-x}$ and its quantity could be controlled directly by varying plasma discharge power.

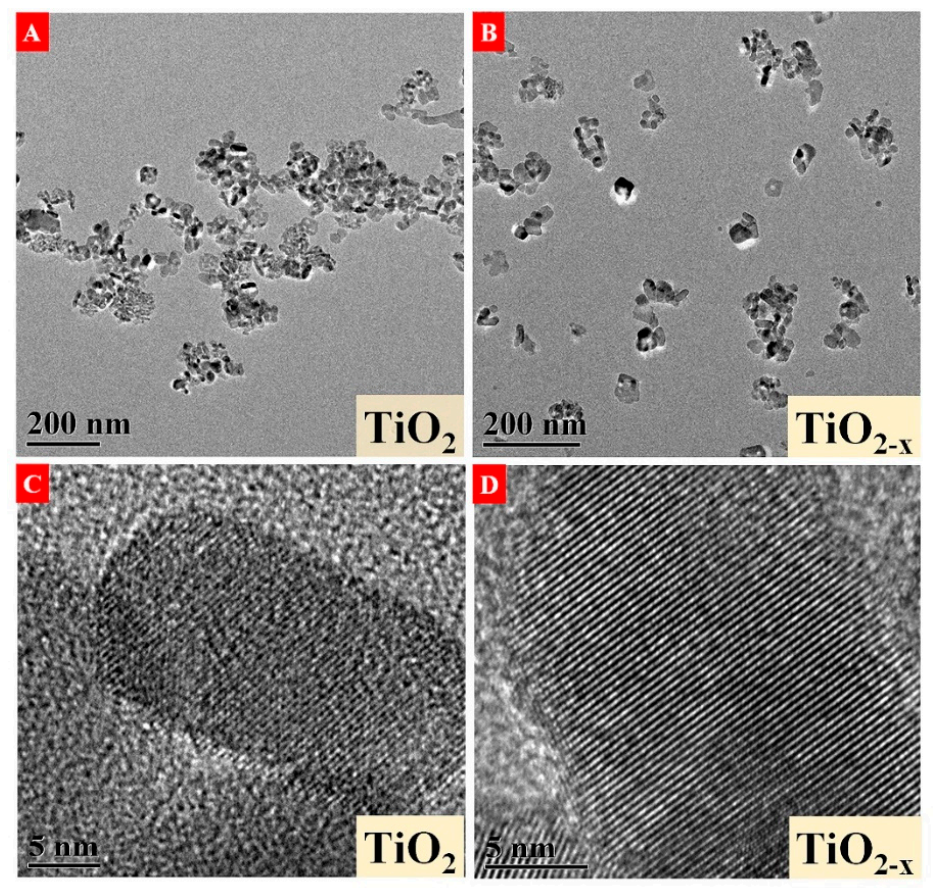

Figure 4. TEM images of $(\mathbf{A}, \mathbf{C})$ pristine $\mathrm{TiO}_{2}$ and $(\mathbf{B}, \mathbf{D})$ gray $\mathrm{TiO}_{2-\mathrm{x}}$.
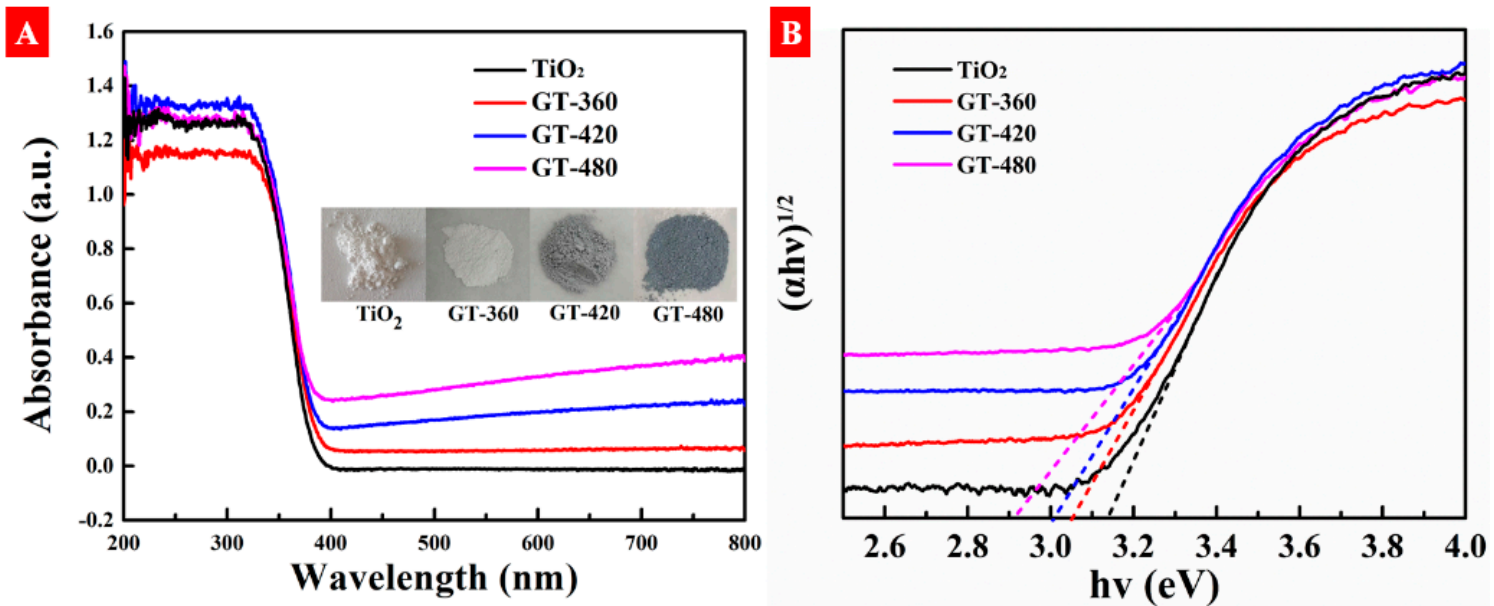

Figure 5. (A) UV-Vis diffuse reflectance spectra of as-prepared samples and the digital photos shown in the inset. (B) The plot of $(\alpha h v)^{1 / 2}$ versus hv using the Kubelka-Munk function. 
The Raman spectra of gray $\mathrm{TiO}_{2-x}$ and pristine $\mathrm{TiO}_{2}$ are shown in Figure 6. Both samples exhibit similar Raman peaks at 142, 194, 395, 514, and $637 \mathrm{~cm}^{-1}$, respectively, which is ascribed to anatase $\mathrm{TiO}_{2}$, well consistent with the XRD results. It is observed that the $\mathrm{E}_{\mathrm{g}}$ mode of anatase associated with the symmetric stretching vibration of $\mathrm{O}-\mathrm{Ti}-\mathrm{O}$ is shifted to higher wavenumbers compared with pristine $\mathrm{TiO}_{2}$, which reveals that the Ti-O bands environment is changed. In principle, this phenomenon can result from lattice defects and/or finite size effect $(<10 \mathrm{~nm})$. Our TEM measurements exclude the size effect as pristine $\mathrm{TiO}_{2}$ and gray $\mathrm{TiO}_{2-x}$ have almost the same nanoparticle size. Consequently, we infer that the difference between gray $\mathrm{TiO}_{2-x}$ and pristine $\mathrm{TiO}_{2}$ is mainly due to the lattice defects effect.

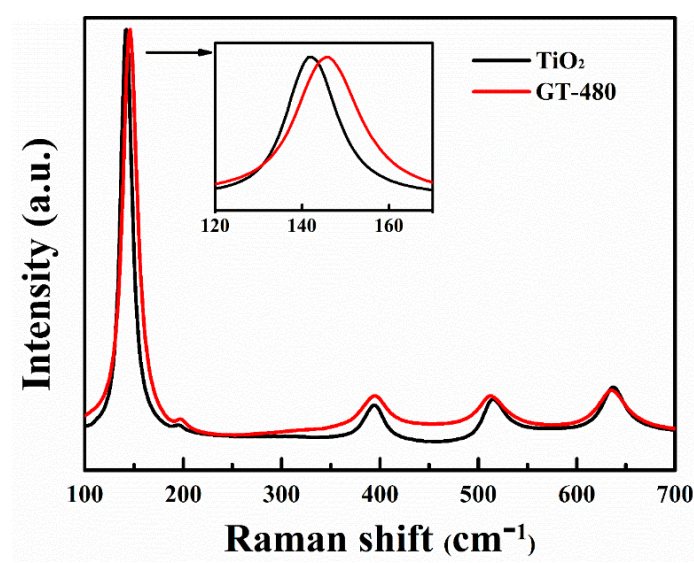

Figure 6. Raman spectra of pristine $\mathrm{TiO}_{2}$ and gray $\mathrm{TiO}_{2-x}$. The inset shows an enlarged view of $\mathrm{E}_{\mathrm{g}}$ mode of pristine $\mathrm{TiO}_{2}$ and gray $\mathrm{TiO}_{2-x}$.

XPS analyses are further performed to investigate the surface chemical states of Ti and O in gray $\mathrm{TiO}_{2-x}$. Figure 7A shows the full-scale XPS spectra of pristine $\mathrm{TiO}_{2}$ and gray $\mathrm{TiO}_{2-x}$. No obvious differences are observed between pristine $\mathrm{TiO}_{2}$ and gray $\mathrm{TiO}_{2-x}$, indicating no other dopant elements in gray $\mathrm{TiO}_{2-\mathrm{x}}$. Figure 7B shows a high-resolution Ti 2p XPS spectra for both samples. There are two main peaks for pristine $\mathrm{TiO}_{2}$ centered at a binding energy of 458.6 and $464.4 \mathrm{eV}$, which are ascribed to $\mathrm{Ti}^{4+} 2 \mathrm{p}_{3 / 2}$ and $\mathrm{Ti}^{4+} 2 \mathrm{p}_{1 / 2}$, respectively [36]. In comparison with pristine $\mathrm{TiO}_{2}$, two similar peaks of gray $\mathrm{TiO}_{2-x}$ are detected but with a slight shift toward lower binding energy at 458.3 and $464 \mathrm{eV}$, assigned to $\mathrm{Ti}^{3+} 2 \mathrm{p}_{3 / 2}$ and $\mathrm{Ti}^{3+} 2 \mathrm{p}_{1 / 2}$, respectively [37]. Figure $7 \mathrm{C}$ shows the XPS $\mathrm{O} 1 \mathrm{~s}$ spectra for pristine $\mathrm{TiO}_{2}$ and gray $\mathrm{TiO}_{2-x}$. From the $\mathrm{O}$ 1s spectrum of pristine $\mathrm{TiO}_{2}$, two deconvoluted peaks at 529.6 and $531.4 \mathrm{eV}$ are related to lattice oxygen (Ti-O) and surface absorption hydroxyl (Ti-OH), respectively [38]. Comparably, the fitting peaks of $\mathrm{O} 1 \mathrm{~s}$ spectrum of gray $\mathrm{TiO}_{2-\mathrm{x}}$ show an obvious shift toward higher binding energy at 529.7 and $531.5 \mathrm{eV}$, which is mainly due to the existence of oxygen vacancies. Moreover, the area of fitting peak of $\mathrm{Ti}-\mathrm{OH}$ in gray $\mathrm{TiO}_{2-x}$ is little larger than that of pristine $\mathrm{TiO}_{2}$, indicating that many $\mathrm{Ti}$ dangling bonds induced by oxygen vacancies are produced.

The existence of surface defects was confirmed by EPR spectra at room temperature as shown in Figure 8. Unexpectedly, the pristine $\mathrm{TiO}_{2}$ shows an apparent paramagnetic signal centered at $\mathrm{g}=2.001$ ascribed to surface oxygen defects, which is consistent with HRTEM measurement. In comparison with $\mathrm{TiO}_{2}$, gray $\mathrm{TiO}_{2-x}$ possesses two extinguished peaks at $\mathrm{g}=2.001$ and $\mathrm{g}=1.974$, corresponding to surface oxygen vacancies and surface $\mathrm{Ti}^{3+}$ species, respectively, which is in good accordance with XPS results $[39,40]$. As is well known, the formation of $\mathrm{Ti}^{3+}$ centers is always accompanied by the presence of oxygen vacancies due to the charge unbalance. It should be noticed that both of the EPR signals gradually increase with plasma discharge power. It is therefore proved that the high concentration of surface defects can be obtained when applying sufficient output energy. 

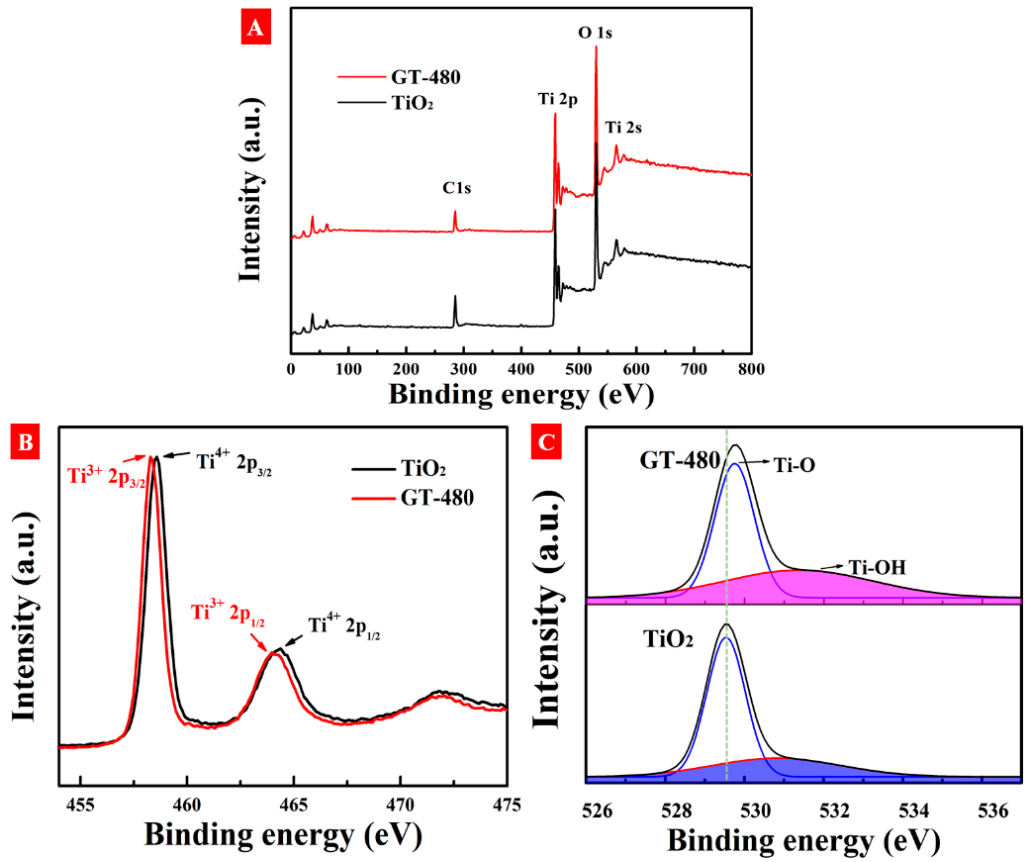

Figure 7. (A) XPS survey spectra, (B) Ti 2p XPS spectra, and (C) O 1s XPS spectra of samples.

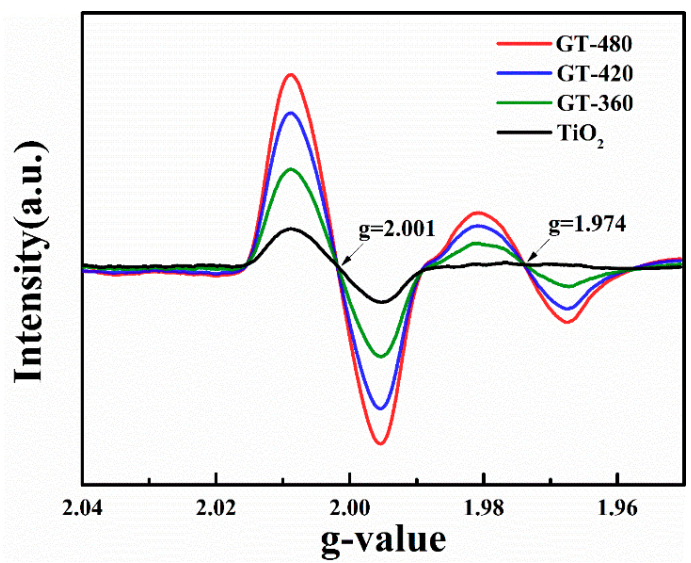

Figure 8. EPR(Electron paramagnetic resonance) spectra of the as-synthesized gray $\mathrm{TiO}_{2-x}$ samples obtained with different plasma discharge powers.

Based on the obtained results, the generation of surface defects in gray $\mathrm{TiO}_{2-x}$ could be understood that hydrogen atoms generated by liquid-plasma electrolysis reduced $\mathrm{TiO}_{2}$ to produce $\mathrm{Ti}^{3+}$ and oxygen vacancies. Furthermore, hydrogen atoms entered in the $\mathrm{TiO}_{2-x}$ lattice and some atoms bonded with $\mathrm{Ti}$ atoms while others bonded with $\mathrm{O}$ atoms, and thus created the surface lattice disorders [41]. Massive hydrogen atoms produced by enhanced output power create an intensified plasma hydrogenation effect, which induces the increased contents of surface $\mathrm{Ti}^{3+}$ and oxygen vacancies [42]. In addition, there is no color fade for gray $\mathrm{TiO}_{2-x}$ even if exposed in air and water for six months, indicating the existences of surface defects are quite stable. The robust surface defects could be attributed to the wrapped outer disorder surface with 1-2 nm thickness, hindering further strong oxidation by liquid plasma. On the other hand, considering the presence of surface $\mathrm{Ti}^{3+}$ and oxygen vacancies, the rather stable point defect structure of $\mathrm{Ti}^{3+}-\mathrm{Vo}^{-} \mathrm{Ti}^{3+}$ could be formed in order to maintain the electrostatic balance [43].

The photocatalytic performance for whole samples was tested with degradation of RhB under visible-light illumination $(\lambda>420 \mathrm{~nm})$, as shown in Figure 9A. It is clearly seen that gray $\mathrm{TiO}_{2-x}$ shows a much higher photoactivity than that of pristine $\mathrm{TiO}_{2}$ and $\mathrm{P} 25$. Figure $9 \mathrm{~B}$ shows the calculated $\ln \left(C_{0} / C_{t}\right)$ with the irradiation time $(t)$, i.e., $\ln \left(C_{0} / C_{t}\right)=k t$, where $k$ is the apparent rate constant, which 
follows first-order kinetic behavior and can directly give the efficiency of photodegradation. The best performance of gray $\mathrm{TiO}_{2-\mathrm{x}}$ is $0.126 \mathrm{~min}^{-1}$, which is far higher than pristine $\mathrm{TiO}_{2}$ and is 6.5 times of P25. In order to evaluate the stability of gray $\mathrm{TiO}_{2-x}$, the photocatalytic reaction was repeated four times under the same experimental conditions. As shown in Figure 9C, after four repeated cycles, the photocatalytic performance has no obvious differences, which indicates that the photoactivity of gray $\mathrm{TiO}_{2-x}$ is rather stable. Additionally, the visible-light degradation of methyl orange and phenol are shown in Figure 9D. After $2 \mathrm{~h}$ of photodegradation, the degradation rate of $\mathrm{MO}$ using gray $\mathrm{TiO}_{2-\mathrm{x}}$ is $96.25 \%$, while pristine $\mathrm{TiO}_{2}$ shows only $7.52 \%$. The degradation rate of phenol for pristine $\mathrm{TiO}_{2}$ is $4.26 \%$, while gray $\mathrm{TiO}_{2-x}$ shows a much higher rate than pristine $\mathrm{TiO}_{2}$ and reaches $89.2 \%$. Furthermore, some hydrogenated titania and doped $\mathrm{TiO}_{2}$ with high performance in $\mathrm{RhB}$ photodegradation are provided for comparison with gray $\mathrm{TiO}_{2-x}$ as reflected in Table 1.

On basis of the above results, we can conclude that the superior photocatalytic activity of gray- $\mathrm{TiO}_{2-x}$ is mainly due to the existence of surface defects. It is generally accepted that photocatalytic activity is largely dependent on the quantity of absorbed photons. The more photons $\mathrm{TiO}_{2}$ can absorb, the more photoinduced electrons and holes it can produce. Owing to the existence of oxygen vacancies and $\mathrm{Ti}^{3+}$ centers, dopants states such as $\mathrm{Ti}^{3+}$ states and oxygen states appear between the bandgap, which can narrow the bandgap and allow more long-wavelength light absorption. Even though, lots of photoinduced e-h pairs yet are easily recombined in the bulk of $\mathrm{TiO}_{2}$ crystal, leading to a serious waste of photoinduced charges. Surface defects serve as holes absorbers and thus cause the directional diffusion of photogenerated e-h pairs to the $\mathrm{TiO}_{2}$ surface. Therefore, benefits of surface defects in gray $\mathrm{TiO}_{2-x}$ not only narrow its bandgap, but also reduce the recombination rate of e-h pairs. On the other hand, with the increase of output energy, the concentrations of surface defects are correspondingly improved, and lead to a narrower bandgap, as well as faster e-h pairs diffusion. It thus explains discharge power-dependent photoactivity of gray $\mathrm{TiO}_{2-x}$.
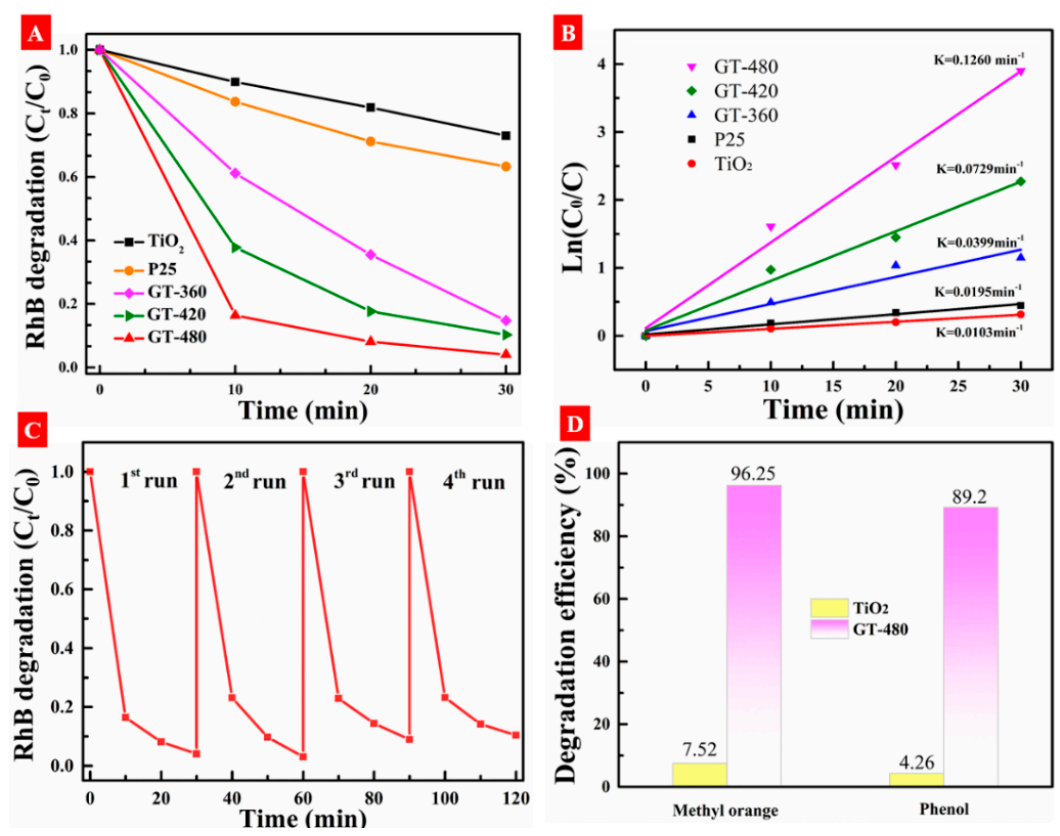

Figure 9. (A) Photocatalytic degradation curves of RhB(Rhodamine B) over different photocatalysts under visible-light irradiation. (B) The pseudo-first-order reaction rate constant for all samples. (C) Recycling test results using GT-480 as the photocatalyst. (D) Photodegradation rates of methyl orange and phenol with $\mathrm{TiO}_{2}$ and GT-480 under visible-light irradiation. 
Table 1. Comparison of rhodamine B photodegradation efficiency over gray $\mathrm{TiO}_{2-\mathrm{x}}$ with reported colored titania and highly efficient photocatalysts.

\begin{tabular}{|c|c|c|c|c|c|c|}
\hline Photocatalyst & Synthesis Method & $\begin{array}{l}\text { Light } \\
\text { Source }\end{array}$ & $\mathrm{C}_{\mathrm{RhB}}$ & $\mathrm{W}_{\text {Cat }}$ & Performance & Ref. \\
\hline Gray $\mathrm{TiO}_{2}$ & $\begin{array}{l}\text { Liquid-plasma hydrogenation } \\
\text { of anatase } \mathrm{TiO}_{2}\end{array}$ & $\begin{array}{l}\text { Visible light } \\
300 \mathrm{~W}\end{array}$ & $50 \mathrm{~mL} \mathrm{RhB}, 20$ ppm & $50 \mathrm{mg}$ & $\mathrm{T}_{90 \%}=20 \mathrm{~min}$ & This work \\
\hline Black $\mathrm{TiO}_{2}$ & $\begin{array}{l}\text { Hydrogen plasma assisted } \\
\text { chemical vapor deposition }\end{array}$ & $\begin{array}{l}\text { Solar light } \\
50 \mathrm{~W}\end{array}$ & $50 \mathrm{~mL} \mathrm{RhB}, 2 \mathrm{mg} / \mathrm{L}$ & $10 \mathrm{mg}$ & $\mathrm{T}_{90 \%}=20 \mathrm{~min}$ & [44] \\
\hline Blue $\mathrm{TiO}_{2}$ & $\begin{array}{l}\text { Hydrothermal treatment } \\
\text { and annealing in } \\
\text { argon environment }\end{array}$ & $\begin{array}{l}\text { Visible light } \\
350 \mathrm{~W}\end{array}$ & $30 \mathrm{~mL} \mathrm{RhB}, 10 \mathrm{mg} / \mathrm{L}$ & $20 \mathrm{mg}$ & $\mathrm{T}_{90 \%}=150 \mathrm{~min}$ & [45] \\
\hline Blue $\mathrm{TiO}_{2}$ & $\begin{array}{l}\text { Solvothermal reaction } \\
\text { with } \mathrm{TiCl}_{3} \text { solution }\end{array}$ & $\begin{array}{l}\text { Visible light } \\
500 \mathrm{~W}\end{array}$ & $50 \mathrm{~mL} \mathrm{RhB}, 10 \mathrm{mg} / \mathrm{L}$ & $100 \mathrm{mg}$ & $\mathrm{T}_{90 \%}=110 \mathrm{~min}$ & [46] \\
\hline Black $\mathrm{TiO}_{2}$ & $\begin{array}{l}\text { Ultraviolet light irradiation and } \\
\text { low temperature annealing }\end{array}$ & $\begin{array}{l}\text { Solar light } \\
500 \mathrm{~W}\end{array}$ & $40 \mathrm{~mL} \mathrm{RhB}, 4 \times 10^{-5} \mathrm{M}$ & $10 \mathrm{mg}$ & $\mathrm{T}_{90 \%}=130 \mathrm{~min}$ & [47] \\
\hline Gray $\mathrm{TiO}_{2}$ & $\begin{array}{l}\text { Anodization and liquid } \\
\text { plasma hydrogenation }\end{array}$ & $\begin{array}{l}\text { Visible light } \\
300 \mathrm{~W}\end{array}$ & $50 \mathrm{~mL} \mathrm{RhB}, 20$ ppm & $50 \mathrm{mg}$ & $\mathrm{T}_{90 \%}=70 \mathrm{~min}$ & [25] \\
\hline Brown $\mathrm{TiO}_{2}$ & $\begin{array}{l}\text { Noble metal deposited on } \\
\text { defective } \mathrm{TiO}_{2-x}\end{array}$ & $\begin{array}{l}\text { Visible light } \\
300 \mathrm{~W}\end{array}$ & $10 \mathrm{uM} \mathrm{RhB}, 80 \mathrm{~mL}$ & $80 \mathrm{mg}$ & $\mathrm{T}_{90 \%}=120 \mathrm{~min}$ & [48] \\
\hline Gray $\mathrm{TiO}_{2}$ & $\begin{array}{l}\text { Hydrogen plasma-treated } \\
\text { nanoporous } \mathrm{TiO}_{2}\end{array}$ & $\begin{array}{l}\text { Solar light } \\
150 \mathrm{~W}\end{array}$ & $3 \mathrm{mg} / \mathrm{mL} \mathrm{RhB}$ & $0.5 \mathrm{~g} / \mathrm{L}$ & $\mathrm{T}_{90 \%}=90 \mathrm{~min}$ & [49] \\
\hline Black $\mathrm{TiO}_{2}$ & $\begin{array}{l}\text { Reduced by } \mathrm{NaBH}_{4} \text { under } \\
\text { argon atmosphere. }\end{array}$ & $\begin{array}{l}\text { Solar light } \\
300 \mathrm{~W}\end{array}$ & $50 \mathrm{~mL} \mathrm{RhB}, 5 \mathrm{ppm}$ & $50 \mathrm{mg}$ & $\mathrm{T}_{90 \%}=50 \mathrm{~min}$ & [50] \\
\hline $\mathrm{Ar}-\mathrm{TiO}_{2}$ & $\begin{array}{l}\text { Argon plasma treatments in a } \\
\text { dielectric barrier discharge }\end{array}$ & $\begin{array}{l}\text { Visible light } \\
300 \mathrm{~W}\end{array}$ & $100 \mathrm{~mL}$ RhB $10 \mathrm{mg} / \mathrm{L}$ & $50 \mathrm{mg}$ & $\mathrm{T}_{90 \%}=90 \mathrm{~min}$ & [51] \\
\hline Graphene-P25 & $\begin{array}{l}\text { Hydrothermal reaction of } \\
\text { graphene and P25 }\end{array}$ & $\begin{array}{l}\text { Solar light } \\
100 \mathrm{~W}\end{array}$ & $100 \mathrm{~mL} \mathrm{RhB}, 0.03 \mathrm{mmol} / \mathrm{L}$ & $6.3 \mathrm{mg}$ & $\mathrm{T}_{90 \%}=15 \mathrm{~min}$ & [52] \\
\hline $\begin{array}{c}\text { Pt-doped } \\
\text { nanoporous } \mathrm{TiO}_{2}\end{array}$ & $\begin{array}{l}\text { Sol-gel hydrothermal and } \\
\text { annealing under } \\
\mathrm{H}_{2} \text { atmosphere }\end{array}$ & $\begin{array}{l}320-500 \mathrm{~nm} \\
220 \mathrm{~W}\end{array}$ & $10 \mathrm{~mL} \mathrm{RhB}, 10 \mathrm{ppm}$ & $3 \mathrm{mg}$ & $\mathrm{T}_{90 \%}>180 \mathrm{~min}$ & [53] \\
\hline
\end{tabular}

$\mathrm{C}_{\mathrm{RhB}}$ : Initial RhB concentration; $\mathrm{W}_{\text {cat }}$ : Catalyst usage; and $\mathrm{T}_{90 \%}$ : Time $90 \%$ conversion of RhB; Ref.: Reference.

Considering the high temperature involved in liquid plasma treatments (2000-3000 K), the possible modification of black $\mathrm{TiO}_{2}$ deriving from the titanium cathodes should be discussed. Originally, we carried out the liquid plasma experiment to produce black $\mathrm{TiO}_{2}$, which was reported by others [16-18]. Typically, Ti cathodes (99.9\%) and Pt anode (99.99\%) were used and all other experimental conditions and setup are same with this work, except no $\mathrm{TiO}_{2}$ powder was mixed in the electrolyte. The black $\mathrm{TiO}_{2}$ nanoparticles were derived from Ti cathodes after plasma anodization and heat treatment, which shows abundant surface oxygen vacancies. However, the quantity of black $\mathrm{TiO}_{2}$ is quite few (about $10 \mathrm{mg}$ ), and it cannot meet our demands in the experiment and some practical applications. Furthermore, visible-light photodegradation of black $\mathrm{TiO}_{2}$ shows a heavy decrease in photocatalytic performance, which was ascribed to unstable existences of surface oxygen vacancies due to photocorrosion. To improve the quantity and photocatalytic performance, lots of anatase $\mathrm{TiO}_{2}$ powders were added and mixed in the electrolyte, which subsequently produced gray $\mathrm{TiO}_{2-x}$ with mass production and stable surface defects. Overall, the contamination of black $\mathrm{TiO}_{2}$ generated from Ti cathodes existed. Nevertheless, the stabilities of surface oxygen defects, as well as photodegradation performance exhibited in gray $\mathrm{TiO}_{2-x}$, which confirms that the mechanism of plasma power-related hydrogenation with $\mathrm{TiO}_{2}$ plays the major role in whole synthesis procedure. Therefore, contamination from Ti cathodes does not affect the performance of gray $\mathrm{TiO}_{2-x}$, and the modification can be ignored. On the other hand, platinum sheet as inert metals is resisted by heavy corrosion due to intense plasma anodization, and there is no mass decay of $\mathrm{Pt}$ anode after plasma treatments. Transmission electron microscopy-energy dispersive X-ray spectroscopy (TEM-EDS) was carried out to exclude the influence of Pt element as seen in Figure S1.

\section{Conclusions}

In summary, a simple green method assisted by liquid plasma has been demonstrated for the synthesis of gray $\mathrm{TiO}_{2-x}$ at a low temperature and atmospheric pressure. The synthesis mechanism can be explained that the in situ production of plasma-induced hydrogen atoms plays significant roles in 
the hydrogenation reactions of gray $\mathrm{TiO}_{2-x}$. The liquid-plasma technique can effectively manipulate the optical properties and band structures of gray $\mathrm{TiO}_{2-x}$, and herein enhances accompanying visible-light absorption. One interesting finding is that the engineered surface defects can be realized through directly controlling the plasma discharge power. EPR measurements confirm the existences of surface oxygen vacancies and $\mathrm{Ti}^{3+}$ species in gray $\mathrm{TiO}_{2-x}$. Both kinds of defects concentrations are well controllable and increase with the output plasma power. The synergistic effect with narrowed bandgap and directional e-h pairs diffusion results in superior visible-light photoactivity. Rhodamine B was used to evaluate the visible-light photodegradation performance. The results show that the removal rate constant of gray $\mathrm{TiO}_{2-x}$ reaches $0.126 \mathrm{~min}^{-1}$, and is 6.5 times of P25. Moreover, photodegradations of methyl orange and phenol confirm that gray $\mathrm{TiO}_{2-x}$ exhibits much higher photoactivity than pristine $\mathrm{TiO}_{2}$. We believe that this liquid plasma hydrogenation strategy can be extended to other photocatalysts with mass stable surface defects. Overall, our gray $\mathrm{TiO}_{2-x}$ with improved solar energy absorption possesses potential for more efficient polluted water cleaning.

Supplementary Materials: The following are available online at http://www.mdpi.com/2079-4991/10/2/342/s1, Figure S1: (A) The selected area for elements analysis in TEM of Ti420, and (B) the EDS resulte, Table S1: The integrated peak area of the diffraction peak at (101) facet.

Author Contributions: Data curation and writing—original draft preparation, F.Z.; conceptualization, methodology, supervision, and editing, G.F.; visualization and investigation, M.H.; writing—reviewing, Y.H.; writing—reviewing and funding acquisition, H.Z. All authors have read and agreed to the published version of the manuscript.

Funding: This research was funded by the National Key Research and Development Program of China (2018YFB0407100, 2018YFB0504400), the National Natural Science Foundation of China (11727812 and 11621404), and Key Projects from Shanghai S\&T Commission (18JC1412000) and Shanghai Educational Commission (2017-01-07-00-05-E000021)

Conflicts of Interest: The authors declare no competing financial interest.

\section{References}

1. Fujishima, A.; Honda, K. Electrochemical photolysis of water at a semiconductor electrode. Nature 1972, 238, 37-38. [CrossRef]

2. Grätzel, M. Photoelectrochemical cells. Nature 2001, 414, 338-344. [CrossRef]

3. Linsebigler, A.L.; Lu, G.; Yates, J.T. Photocatalysis on $\mathrm{TiO}_{2}$ surfaces: Principles, mechanisms, and selected results. Chem. Rev. 1995, 95, 735-758. [CrossRef]

4. Guo, Q.; Zhang, Z.; Ma, X.; Jing, K.; Shen, M.; Yu, N.; Tang, J.; Dionysiou, D.D. Preparation of N,F-codoped $\mathrm{TiO}_{2}$ nanoparticles by three different methods and comparison of visible-light photocatalytic performances. Sep. Purif. Technol. 2017, 175, 305-313. [CrossRef]

5. Chen, Q.; Zhang, Y.; Zhang, D.; Yang, Y. Ag and N co-doped $\mathrm{TiO}_{2}$ nanostructured photocatalyst for printing and dyeing wastewater. J. Water Process Eng. 2017, 16, 14-20. [CrossRef]

6. Daté, M.; Haruta, M. Moisture effect on $\mathrm{CO}$ oxidation over $\mathrm{Au} / \mathrm{TiO}_{2}$ catalyst. J. Catal. 2001, 201, 221-224. [CrossRef]

7. Vaiano, V.; Iervolino, G.; Sannino, D.; Murcia, J.J.; Hidalgo, M.C.; Ciambelli, P.; Navío, J.A. Photocatalytic removal of patent blue $\mathrm{V}$ dye on $\mathrm{Au}-\mathrm{TiO}_{2}$ and $\mathrm{Pt}_{-} \mathrm{TiO}_{2}$ catalysts. Appl. Catal. B Environ. 2016, 188, 134-146. [CrossRef]

8. Lin, Y.-H.; Hsueh, H.-T.; Chang, C.-W.; Chu, H. The visible light-driven photodegradation of dimethyl sulfide on S-doped $\mathrm{TiO}_{2}$ : Characterization, kinetics, and reaction pathways. Appl. Catal. B Environ. 2016, 199, 1-10. [CrossRef]

9. Xiang, P.; Lv, F.; Xiao, T.; Jiang, L.; Tan, X.; Shu, T. Improved performance of quasi-solid-state dye-sensitized solar cells based on iodine-doped $\mathrm{TiO}_{2}$ spheres photoanodes. J. Alloy. Compd. 2018, 741, 1142-1147. [CrossRef]

10. Chen, X.; Burda, C. The Electronic origin of the visible-light absorption properties of C-, N- and S-doped $\mathrm{TiO}_{2}$ nanomaterials. J. Am. Chem. Soc. 2008, 130, 5018-5019. [CrossRef]

11. Zhang, K.; Park, J.H. Surface localization of defects in black $\mathrm{TiO}_{2}$ : Enhancing photoactivity or reactivity. J. Phys. Chem. Lett. 2017, 8, 199-207. [CrossRef] [PubMed]

12. Wu, P.; Dai, S.; Chen, G.; Zhao, S.; Xu, Z.; Fu, M.; Chen, P.; Chen, Q.; Jin, X.; Qiu, Y.; et al. Interfacial effects in hierarchically porous $\alpha-\mathrm{MnO}_{2} / \mathrm{Mn}_{3} \mathrm{O}_{4}$ heterostructures promote photocatalytic oxidation activity. Appl. Catal. $B$ Environ. 2019, 118418. [CrossRef] 
13. Zuo, F.; Wang, L.; Wu, T.; Zhang, Z.; Borchardt, D.; Feng, P. Self-doped $\mathrm{Ti}^{3+}$ enhanced photocatalyst for hydrogen production under visible light. J. Am. Chem. Soc. 2010, 132, 11856-11857. [CrossRef] [PubMed]

14. Xia, T.; Chen, X. Revealing the structural properties of hydrogenated black $\mathrm{TiO}_{2}$ nanocrystals. J. Mater. Chem. A 2013, 1, 2983-2989. [CrossRef]

15. Chen, X.; Liu, L.; Huang, F. Black titanium dioxide $\left(\mathrm{TiO}_{2}\right)$ nanomaterials. Chem. Soc. Rev. 2015, 44, 1861-1885. [CrossRef]

16. Li, L.; Song, L.; Zhu, L.; Yan, Z.; Cao, X. Black $\mathrm{TiO}_{2-\mathrm{x}}$ with stable surface oxygen vacancies as the support of efficient gold catalysts for water-gas shift reaction. Catal. Sci. Technol. 2018, 8, 1277-1287. [CrossRef]

17. Liu, N.; Schneider, C.; Freitag, D.; Hartmann, M.; Venkatesan, U.; Müller, J.; Spiecker, E.; Schmuki, P. Black $\mathrm{TiO}_{2}$ nanotubes: Cocatalyst-free open-circuit hydrogen generation. Nano Lett. 2014, 14, 3309-3313. [CrossRef]

18. Panomsuwan, G.; Watthanaphanit, A.; Ishizaki, T.; Saito, N. Water-plasma-assisted synthesis of black titania spheres with efficient visible-light photocatalytic activity. Phys. Chem. Chem. Phys. 2015, 17, 13794-13799. [CrossRef]

19. Zhang, H.; Cai, J.; Wang, Y.; Wu, M.; Meng, M.; Tian, Y.; Li, X.; Zhang, J.; Zheng, L.; Jiang, Z.; et al. Insights into the effects of surface/bulk defects on photocatalytic hydrogen evolution over $\mathrm{TiO}_{2}$ with exposed 001 facets. Appl. Catal. B Environ. 2018, 220, 126-136. [CrossRef]

20. Kong, M.; Li, Y.; Chen, X.; Tian, T.; Fang, P.; Zheng, F.; Zhao, X. Tuning the relative concentration ratio of bulk defects to surface defects in $\mathrm{TiO}_{2}$ nanocrystals leads to high photocatalytic efficiency. J. Am. Chem. Soc. 2011, 133, 16414-16417. [CrossRef]

21. Ullattil, S.G.; Periyat, P. Microwave-power induced green synthesis of randomly oriented mesoporous anatase $\mathrm{TiO}_{2}$ nanoparticles for efficient dye sensitized solar cells. Sol. Energy 2017, 147, 99-105. [CrossRef]

22. Ullattil, S.G.; Narendranath, S.B.; Pillai, S.C.; Periyat, P. Black $\mathrm{TiO}_{2}$ nanomaterials: A review of recent advances. Chem. Eng. J. 2018, 343, 708-736. [CrossRef]

23. Lepcha, A.; Maccato, C.; Mettenbörger, A.; Andreu, T.; Mayrhofer, L.; Walter, M.; Olthof, S.; Ruoko, T.P.; Klein, A.; Moseler, M.; et al. Electrospun black titania nanofibers: Influence of hydrogen plasma-induced disorder on the electronic structure and photoelectrochemical performance. J. Phys. Chem. C 2015, 119, 18835-18842. [CrossRef]

24. Zimbone, M.; Buccheri, M.A.; Cacciato, G.; Sanz, R.; Rappazzo, G.; Boninelli, S.; Reitano, R.; Romano, L.; Privitera, V.; Grimaldi, M.G. Photocatalytical and antibacterial activity of $\mathrm{TiO}_{2}$ nanoparticles obtained by laser ablation in water. Appl. Catal. B Environ. 2015, 165, 487-494. [CrossRef]

25. Feng, G.; Wu, B.; Khan, A.Q.; Zeng, H. In situ glow discharge plasma electrolytic synthesis of reduced $\mathrm{TiO}_{2}$ for enhanced visible light photocatalysis. Mater. Res. Express 2018, 5, 055022. [CrossRef]

26. Jedsukontorn, T.; Ueno, T.; Saito, N.; Hunsom, M. Facile preparation of defective black $\mathrm{TiO}_{2}$ through the solution plasma process: Effect of parametric changes for plasma discharge on its structural and optical properties. J. Alloy. Compd. 2017, 726, 567-577. [CrossRef]

27. Wang, K.; Xu, M.; Gu, Y.; Gu, Z.; Liu, J.; Fan, Q.H. Low-temperature plasma exfoliated n-doped graphene for symmetrical electrode supercapacitors. Nano Energy 2017, 31, 486-494. [CrossRef]

28. Mauchauffé, R.; Bonot, S.; Moreno-Couranjou, M.; Detrembleur, C.; Boscher, N.D.; Van De Weerdt, C.; Duwez, A.-S.; Choquet, P. Fast Atmospheric plasma deposition of bio-inspired catechol/quinone-rich nanolayers to immobilize NDM-1 enzymes for water treatment. Adv. Mater. Interfaces 2016, 3, 1500520. [CrossRef]

29. Gupta, P.; Tenhundfeld, G.; Daigle, E.O.; Ryabkov, D. Electrolytic plasma technology: Science and engineering-An overview. Surf. Coat. Technol. 2007, 201, 8746-8760. [CrossRef]

30. Bruggeman, P.; Leys, C. Non-thermal plasmas in and in contact with liquids. J. Phys. D Appl. Phys. 2009, 42, 053001. [CrossRef]

31. Chen, Q.; Li, J.; Li, Y. A review of plasma-liquid interactions for nanomaterial synthesis. J. Phys. D Appl. Phys. 2015, 48, 424005. [CrossRef]

32. Bardos, L.; Baránková, H.; Bardos, A. Production of hydrogen-rich synthesis gas by pulsed atmospheric plasma submerged in mixture of water with ethanol. Plasma Chem. Plasma Process. 2017, 37, 115-123. [CrossRef]

33. Zhu, Q.; Peng, Y.; Lin, L.; Fan, C.-M.; Gao, G.-Q.; Wang, R.-X.; Xu, A.-W. Stable blue $\mathrm{TiO}_{2-x}$ nanoparticles for efficient visible light photocatalysts. J. Mater. Chem. A 2014, 2, 4429-4437. [CrossRef]

34. Kuznetsov, V.N.; Serpone, N. On the origin of the spectral bands in the visible absorption spectra of visible-light-active $\mathrm{TiO}_{2}$ specimens analysis and assignments. J. Phys. Chem. C 2009, 113, 15110-15123. [CrossRef] 
35. Wang, Y.; Feng, C.; Zhang, M.; Yang, J.; Zhang, Z. Visible light active N-doped $\mathrm{TiO}_{2}$ prepared from different precursors: Origin of the visible light absorption and photoactivity. Appl. Catal. B Environ. 2011, 104, $268-274$. [CrossRef]

36. Moslah, C.; Aguilar, T.; Alcántara, R.; Ksibi, M.; Navas, J. Synthesis of W-doped $\mathrm{TiO}_{2}$ by low-temperature hydrolysis: Effects of annealing temperature and doping content on the surface microstructure and photocatalytic activity. J. Chin. Chem. Soc. 2019, 66, 99-109. [CrossRef]

37. Hao, W.; Li, X.; Qin, L.; Han, S.; Kang, S.-Z. Facile preparation of $\mathrm{Ti}^{3+}$ self-doped $\mathrm{TiO}_{2}$ nanoparticles and their dramatic visible photocatalytic activity for the fast treatment of highly concentrated $\mathrm{Cr}(\mathrm{vi})$ effluent. Catal. Sci. Technol. 2019, 9, 2523-2531. [CrossRef]

38. Zheng, Z.; Huang, B.; Lu, J.; Wang, Z.; Qin, X.; Zhang, X.; Dai, Y.; Whangbo, M.-H. Hydrogenated titania: Synergy of surface modification and morphology improvement for enhanced photocatalytic activity. Chem. Commun. 2012, 48, 5733-5735. [CrossRef]

39. Li, L.; Yu, L.; Lin, Z.; Yang, G. Reduced $\mathrm{TiO}_{2}$-graphene oxide heterostructure as broad spectrum-driven efficient water-splitting photocatalysts. ACS Appl. Mater. Interfaces 2016, 8, 8536-8545. [CrossRef]

40. Hamdy, M.S.; Saputera, W.H.; Groenen, E.J.; Mul, G. A novel $\mathrm{TiO}_{2}$ composite for photocatalytic wastewater treatment. J. Catal. 2014, 310, 75-83. [CrossRef]

41. Chen, X.; Liu, L.; Yu, P.Y.; Mao, S.S. Increasing Solar absorption for photocatalysis with black hydrogenated titanium dioxide nanocrystals. Science 2011, 331, 746. [CrossRef] [PubMed]

42. Deskins, N.A.; Rousseau, R.; Dupuis, M. Distribution of $\mathrm{Ti}^{3+}$ surface sites in reduced $\mathrm{TiO}_{2}$. J. Phys. Chem. C 2011, 115, 7562-7572. [CrossRef]

43. Yu, X.; Kim, B.; Kim, Y.K. Highly enhanced photoactivity of anatase $\mathrm{TiO}_{2}$ nanocrystals by controlled hydrogenation-induced surface defects. ACS Catal. 2013, 3, 2479-2486. [CrossRef]

44. Teng, F.; Li, M.; Gao, C.; Zhang, G.; Zhang, P.; Wang, Y.; Chen, L.; Xie, E. Preparation of black $\mathrm{TiO}_{2}$ by hydrogen plasma assisted chemical vapor deposition and its photocatalytic activity. Appl. Catal. B Environ. 2014, 148-149, 339-343. [CrossRef]

45. Zhang, Y.; Xing, Z.; Liu, X.; Li, Z.; Wu, X.; Jiang, J.; Li, M.; Zhu, Q.; Zhou, W. Ti ${ }^{3+}$ self-doped blue TiO 2 (b) single-crystalline nanorods for efficient solar-driven photocatalytic performance. ACS Appl. Mater. Interfaces 2016, 8, 26851-26859. [CrossRef]

46. Zhou, Y.; Chen, C.; Wang, N.; Li, Y.; Ding, H. Stable Ti ${ }^{3+}$ Self-doped anatase-rutile mixed $\mathrm{TiO}_{2}$ with enhanced visible light utilization and durability. J. Phys. Chem. C 2016, 120, 6116-6124. [CrossRef]

47. Chen, S.; Wang, Y.; Li, J.; Hu, Z.; Zhao, H.; Xie, W.; Wei, Z. Synthesis of black $\mathrm{TiO}_{2}$ with efficient visible-light photocatalytic activity by ultraviolet light irradiation and low temperature annealing. Mater. Res. Bull. 2018, 98, 280-287. [CrossRef]

48. Pei, Z.; Ding, L.; Feng, W.; Weng, S.; Liu, P. Defect self-doped $\mathrm{TiO}_{2}$ for visible light activity and direct noble metal anchoring. Phys. Chem. Chem. Phys. 2014, 16, 21876-21881. [CrossRef]

49. An, H.-R.; Park, S.Y.; Kim, H.; Lee, C.Y.; Choi, S.; Lee, S.C.; Seo, S.; Park, E.C.; Oh, Y.-K.; Song, C.-G.; et al. Advanced nanoporous $\mathrm{TiO}_{2}$ photocatalysts by hydrogen plasma for efficient solar-light photocatalytic application. Sci. Rep. 2016, 6, 29683. [CrossRef]

50. Ariyanti, D.; Mills, L.; Dong, J.; Yao, Y.; Gao, W. $\mathrm{NaBH}_{4}$ modified $\mathrm{TiO}_{2}$ : Defect site enhancement related to its photocatalytic activity. Mater. Chem. Phys. 2017, 199, 571-576. [CrossRef]

51. Li, Y.; Wang, W.; Wang, F.; Di, L.; Yang, S.; Zhu, S.; Yao, Y.; Ma, C.; Dai, B.; Yu, F. Enhanced photocatalytic degradation of organic dyes via defect-rich $\mathrm{TiO}_{2}$ prepared by dielectric barrier discharge plasma. Nanomaterials 2019, 9, 720. [CrossRef] [PubMed]

52. Liang, Y.; Wang, H.; Sanchez Casalongue, H.; Chen, Z.; Dai, H. TiO 2 nanocrystals grown on graphene as advanced photocatalytic hybrid materials. Nano Res. 2010, 3, 701-705. [CrossRef]

53. Pol, R.; Guerrero, M.; García-Lecina, E.; Altube, A.; Rossinyol, E.; Garroni, S.; Baró, M.D.; Pons, J.; Sort, J.; Pellicer, E. Ni-, Pt- and (Ni/Pt)-doped $\mathrm{TiO}_{2}$ nanophotocatalysts: A smart approach for sustainable degradation of Rhodamine B dye. Appl. Catal. B Environ. 2016, 181, 270-278. [CrossRef]

(C) 2020 by the authors. Licensee MDPI, Basel, Switzerland. This article is an open access article distributed under the terms and conditions of the Creative Commons Attribution (CC BY) license (http://creativecommons.org/licenses/by/4.0/). 